\title{
COMPARISON OF POST PLACENTAL INTRAUTERINE CONTRACEPTIVE DEVICE INSERTION BETWEEN VAGINAL DELIVERY AND CAESAREAN SECTION IN A TERTIARY CARE HOSPITAL
}

\author{
Saira Tasneem, Sanum Kashif, Erum Pervaiz, Faisal Azam \\ Frontier Corps Hospital, Quetta/National University of Medical Sciences (NUMS) Pakistan
}

\begin{abstract}
Objective: To compare the acceptability of insertion of post placental intra uterine contraceptive device, with respect to gravidity between vaginal deliveries and caesarean sections.

Study Design: Prospective comparative study.

Place and Duration of Study: Frontier Corp Hospital, Quetta, from Jan 2019 to Jan 2020.

Methodology: A total of 399 females with age of 18 to 45 years with gravidity (primi, multi and grand multi gravida) were counselled during antenatal visits about benefits and risks of post placental intrauterine contraceptive device (PPIUCD) insertion. For complications, females were assessed at 1 and 6 weeks after delivery.

Results: A total of 399 females with mean age $27.95 \pm 5.07$ years were included in study. About 235 (55.9\%) women delivered vaginally and $164(41.4 \%)$ women by caesarean section. Acceptance rate was $3.8 \%$ and $4.3 \%$ for vaginal and caesarean deliveries respectively. Eleven (73.3\%) women were grand multi gravida and 4 women $(26.6 \%)$ were multi gravid in vaginal delivery acceptance group versus 8 women $(47 \%)$ grand multi and 9 women $(52.9 \%)$ multi gravida in caesarean acceptance group. Five $(15 \%)$ females presented with complications (3 with abdominal pain and 1 each with infection and expulsion).

Conclusion: The overall acceptance rate of PPIUCD was low in this study, the acceptance rate was higher in women undergoing normal vaginal delivery (NVD) as compared to lower segment caesarean section (LSCS), similarly more of the grand multiparas accepted the method as compared to other participants however the differences were not statistically significant.
\end{abstract}

Keywords: Caesarean section, Intrauterine contraceptive device, Normal vaginal delivery, Long acting reversible contraceptive.

This is an Open Access article distributed under the terms of the Creative Commons Attribution License (http://creativecommons.org/licenses/by/4.0), which permits unrestricted use, distribution, and reproduction in any medium, provided the original work is properly cited.

\section{INTRODUCTION}

Among highly populated countries, Pakistan is at sixth number, with a current population of 207 million and $5.5 \%$ growth rate. Pakistan has the fertility rate $(3.48)^{1}$. The family planning program in Pakistan was started in 1950 with very limited success rate because of multiple reasons ${ }^{1,2}$. Lack of education and counselling during antepartum period of the patient, myths and side effect's fear are factors that prevent eligible females to accept various methods ${ }^{2}$.

According to the Pakistan Demographic and Health Survey (PDHS), from 2006-2007, use of modern contraceptive method is approximately

Correspondence: Dr Saira Tasneem, Consultant Gynecologist, Frontier Corps Hospital, Quetta Pakistan

Received: 08 Mar 2020; revised received: 21 Apr 2020; accepted: 24 Apr 2020
$22 \%$ in married women of reproductive ages (MWRA) and use of traditional method is $8 \%$, where as $24 \%$ of MWRA would like to use methods of family planning but are not able to do so and that's why, have an Unmet for family planning. In the last 5 years, the use of contraceptive methods has remained the same (34\% in the 20172018 PDHS and 35\% in the 2012-2013 PDHS). A rise in use of contraceptive methods was witnessed earlier between 2006-07 PDHS and 2012-13 PDHS, mostly due to rise in the use of traditional methods from $4 \%$ to $9 \%$ (NIPS and ICF International, 2013) ${ }^{2}$.

Contraceptive methods used in developing countries vary from those used in the developed world. condoms and oral contraceptives are most commonly used methods in developed countries. However, in the developing countries the most 
commonly used method is female sterilization (35\%) followed by intra uterine contraceptive devices (30\%). oral contraceptive pills, condoms and male sterilization usage is $12 \%, 11 \%$ and $4 \%$ respectively ${ }^{3}$.

Contraceptive prevalence rate (CPR) is an indicator of women's health, development and empowerment. The millennium development goal (MDG) could not be achieved in Pakistan despite lots of efforts. CPR is lagging behind and an unmet need for family planning is on a rise ${ }^{4}$. According to the World Health Organization (WHO), "postpartum family planning (PPFP) is focusing on prevention of unintended and closely spaced pregnancies through the first 12 months following childbirth" 4,5 . Therefore, this study intended to evaluate the acceptability of women for postpartum contraceptive device insertion.

The early postpartum period is the best time for insertion of intrauterine contraceptive devices (IUCD) as they are very receptive with respect to contraception at this time. Women have already passed through a tiring period of pregnancy and labor and are therefore motivated for any contraceptive method. Antenatal period or labor is the only time when they visit hospital. Among longacting reversible contraceptives (LARC), IUCD is a safe method with less complications. For couples requesting reliable, highly effective, non-hormonal, reversible and long-acting contraceptive that can be initiated during the immediate postpartum period, intrauterine contraceptive devices (IUCD) is the only family planning method with no negative effect on lactation ${ }^{6}$. Cu-T 380A is approved for the postpartum intrauterine contraception device. The Cu-T $380 \mathrm{~A}$ is very effective. There are only 6 to 8 pregnancies per 100 women in their first year of use. It can be used for ten years continuously or for whatever time period the woman wants to use. In our country, where delivery may be the only time when pregnant women come in contact with healthcare providers, immediate post placentaI IUCD (PPIUCD) insertion approach is more applicable. Other advantages of post placental intrauterine contraceptive device insertion are that interval insertion discomfort can be avoided and bleeding from insertion will be disguised by lochia. Despite the benefits, Immediate PPIUCD insertion acceptance and utilization is very low ${ }^{7}$. IN Govt. facilities due to subsidy long acting reversible contraceptive e.g. $\mathrm{Cu}$ IUCD is available for immediate postpartum use. Therefore, the aim of current study was to determine the role of post placental IUCD insertion for prevention of unintended pregnancies as well as to assess the acceptance rate with associated complications of PPIUCDs among women who gave birth at FC Hospital, Quetta.

\section{METHODOLOGY}

The study was prospective comparative, conducted at FC Hospital Quetta from 1 ${ }^{\text {st }}$ January 2019 to $1^{\text {st }}$ January 2020. Approval of ethical review board (IERB no: CMH-QTA IRB/017) was taken. Case records of department of obstetrics and gynaecology studied and data was collected on Microsoft excel, temporal sampling was used. A total of 399 women with ages 18 to 45 years were counselled during antenatal visits, in early labour (for vaginal delivery) andimmediately before caesarean section about benefits and risks of PPIUCD use (sample size was calculated via WHO sample size calculator ${ }^{20}$. Acceptance rate of post placental contraceptive device insertion was $18.8 \%$ in study considered for sample size calculation. Predesigned was questionnaire used for data collection. Women who had pre mature, pre labour rupture of membrane greater than 18 hours, Haemoglobin less than $8 \mathrm{~g} / \mathrm{dl}$, known uterine anomaly, known copper allergy and postpartum haemorrhage were not included in study. Written informed consent of all patients and their husbands, were taken before insertion. All PPIUCD insertions were performed by consultant gynaecologists. Patients were evaluated for age, gravidity and mode of delivery and reviewed at 1 and 6 weeks after delivery for any complications (infection, expulsion, abdominal pain, missed thread and perforation). At follow up visits, women were enquired about signs and symptoms associated with complications, Abdominal and speculum examinations were performed. If thread was not visible on speculum examination, ultra sound 
was done to confirm presence of intra uterine IUCD or expulsion. Outcome measures were frequency of acceptance of PPIUCD. Association of PPIUCD acceptance with parity and mode of delivery determined. Data was analyses on SPSS version 16 (IBOM). For determining the association between mode of delivery and parity with PPIUCD use, chi- square test was applied. The $p$ value of $\leq 0.05$ was considered significant.

\section{RESULTS}

Total 399 women fulfilled the inclusion criteria, out of which 235 women (59.9\%) delivered by NVD and 164 women (41.4\%) delivered by caesa- group 9 women $(52.9 \%)$ were multi gravida and 8 women $(47 \%)$ were grand multi gravida. None of the primigravida women accepted for PPIUCD insertion in both groups. Distribution of PPIUCD acceptance according to gravidity was shown in table. Complication rate was $15 \%$. Only 5 women presented with minor complications at follow up visits. Three women presented with abdominal pain, 1 woman reported IUCD expulsion and 1 woman presented with pelvic infection. None of the patients presented with missed thread or perforation. Acceptance rate according to mode of delivery and frequency of gravidity were presented in fig- 1 \& 2 respectively.

Table: Comparison of acceptance of post placental intrauterine contraceptive device, according to gravidity and mode of delivery.

\begin{tabular}{l|c|c|c}
\hline \multirow{2}{*}{ Gravidity } & $\begin{array}{c}\text { Post-Placental Intrauterine } \\
\text { Contraceptive Device } \\
\text { (Accepted), } \mathbf{n = 3 2 ( 8 . 1 \% )}\end{array}$ & $\begin{array}{c}\text { Post-Placental Intrauterine } \\
\text { Contraceptive Device } \\
\text { (Not Accepted), } \mathbf{n = 3 6 7} \text { (92\%) }\end{array}$ & \multirow{2}{*}{$\boldsymbol{p \text { -value }}$} \\
\hline Primigravida & - & $60(16.3 \%)$ & \multirow{2}{*}{$<0.001$} \\
\hline Multi gravida & $14(43.7 \%)$ & $258(70.2 \%)$ & \multirow{2}{*}{$<0.001$} \\
\hline Grand Multi Gravida & $18(56.2 \%)$ & $49(13.3 \%)$ & \\
\hline Mode of Delivery & $15(3.8 \%)$ & $220(55.1 \%)$ & \\
\hline Vaginal Delivery & $17(4.3 \%)$ & $147(36.8 \%)$ & \\
\hline
\end{tabular}

rean section. Total 32 women (8\%) accepted for PPIUCD insertion. Fifteen women (3.8\%) accepted among NVD group and acceptance rate was $4.3 \%$ (17 women) among caesarean group. Soacceptance rate was more for operative deliveries.

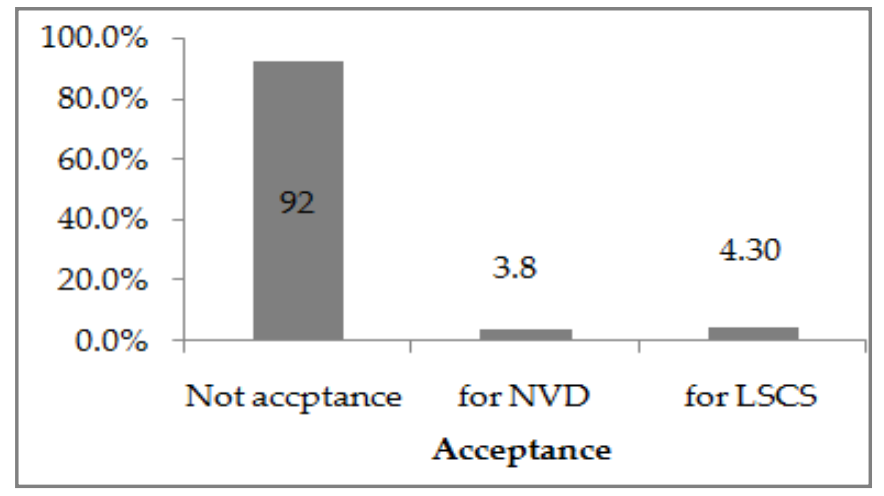

Figure-1: Acceptance rate of PPIUCD according to mode of delivery.

Among NVD acceptance group 11 women $(73.3 \%)$ were grand multigravida and 4 women $(26.6 \%)$ were multi gravida. Among caesarean

\section{DISCUSSION}

The current study found PPIUCD acceptance rate of $8.1 \%, 32$ out of 399 women gave consent for insertion. Mean age was $27.95 \pm 5.07$. Women of age group 25 to 35 years have higher accep-

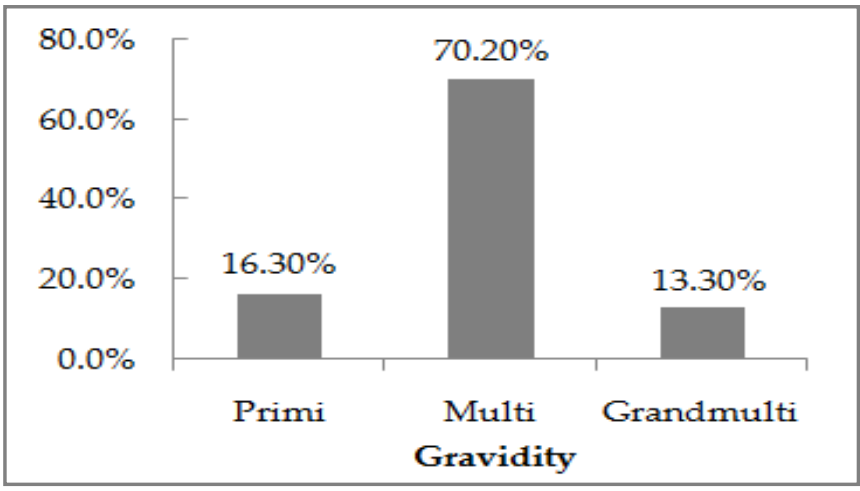

Figure-2: Non acceptance rate of PPIUCD according to gravidity.

tance as compared to age groups 18 to 25 years and 36 to 45 years, acceptance rate was $8.1 \%$ and caesarean deliveries had higher acceptance rate 
as compared to NVD (4.3\% vs 3.8\%). Our study concluded that acceptance rate according to gravidity is $52 \%$ multi gravida in caesarean group vs $26 \%$ multigravida in vaginal delivery group. Our study also found that the majority of those who accepted PPIUCD in the NVD group were grand multigravida as compared to the caesarean group in which most of them were multigravida. One similar study conducted at PIMS hospital Islamabad found that acceptance rate of long acting reversible contraceptive was $8 \%$ and the uptake of postpartum LARC for Primigravida, Multigravida and grand multigravida was $0.6 \%, 9.8 \%$ and $17.8 \%$, respectively ( $p$-value 0.001 ). However this study showed postpartum LARC acceptance similar for vaginal deliveries and caesarean section $(p=0.790)^{8}$. A study conducted at a tertiary care hospital in Egypt had a significantly higher acceptance rate $28.9 \%{ }^{9}$. A study conducted by Mishra et al, also had similar observations. Additionally, Mishra et al also noted that the acceptability was higher among women who had previously closely spaced pregnancies ${ }^{10}$. This again brings to point the fact that PPIUCD is now gaining favor among women as a contraceptive of choice for spacing their pregnancies.

In a study conducted at ranger hospital Lahore, intra caesarean PPIUCD insertions were done and the number of women accepted PPIUCD was around $40 \%$ that is much higher as compared to our study ${ }^{11}$.

A study conducted by Saboohi et al evaluated efficacy, safety and complications of immediate PPIUCD use concluded that $20 \%$ women had a normal vaginal discharge (infection) and $4 \%$ women presented with abdominal pain and spontaneous expulsion occurred in $6 \%$ of cases. Perforation and lost thread was observed in $1 \%$ and $5 \%$ of cases respectively ${ }^{12}$.

A similar study conducted in Bangladesh concluded an acceptance rate of 16\% (almost double as compared to our study. in this study 300 $(87 \%)$ insertions done during cesarean section and $43(12 \%)$ after vaginal delivery ${ }^{13}$.
Our study also evaluated and compared complications. Abdominal pain was observed in 3 patients, 1 patient presented with spontaneous expulsion and 1 patient presented with infection. A study done at federal govt hospital, Islamabad concluded that $47 \%$ patients had no complaints regarding PPIUCD use (Major complaint was vaginal discharge and backache $13 \%$ each). Similarly the complication rate was just $15 \%$ in our study ${ }^{14}$. Gajju et al showed that $18 \%$ women accepted insertion and continuation was seen in $97 \%$ women ${ }^{15}$.

So post placental IUDinsertion as a long term reversible contraceptive method (LARC) is safe ${ }^{16,17}$. In current study, the majority of patients belonged to the 25-35 years age group (mean age 27 years). A retrospective cohort study done in a tertiary care hospital concluded that $58 \%$ of women had intra cesarean insertions and $41 \%$ insertions were performed after vaginal deliveries ${ }^{18}$.

A study published in the international journal of research and review evaluated safety and efficacy also proved post placental insertion to be safe and efficacious ${ }^{19}$.

Acceptance rate in our study was less. This trend shows behaviour of women towards post placental intrauterine contraceptive device use. In our study we noted $92 \%$ women refused post placental intrauterine contraceptive device insertion, which raises a question on unmet needs of these women. Unmet needs are defined as women who want to delay or stop child bearing but they are not using any contraceptive method. More health care professionals should be trained to increase the skill and knowledge regarding PPIUCD use.

The study was conducted at a hospital where most of the patients have low socioeconomic status and have low literacy levels. Secondly, selection of only one study site and limited sample size, limited the study findings external validity. Study participants were followed for only 6 weeks after delivery for complications and efficacy of the method used could not be assessed for long term. 


\section{ACKNOWLEDGMENT}

Authors would like to acknowledge all staff of department of Obstetrics and gynecology who contributed in gathering data and follow up of patients.

\section{CONCLUSION}

The overall acceptance rate of PPIUCD was low in this study, the acceptance rate was higher in women undergoing NVD as compared to LSCS, similarly more of the grand multiparas accepted the method as compared to other participants however the differences were not statistically significant.

\section{CONFLICT OF INTEREST}

This study has no conflict of interest to be declared by any author.

\section{REFERENCES}

1. National Institute of Population Studies (NIPS) [Pakistan] and ICF. 2018. Pakistan Demographic and Health Survey 2017-18. Islamabad, Pakistan, and Rockville, Maryland, USA: NIPS and ICF.

2. National Institute of Population Studies, Macro International Inc. Pakistan demographic and health survey 2017-18. Islamabad: Government of Pakistan; 2018.

3. Darroch JE, Singh S. Trends in contraceptive need and use in developing countries in 2003, 2008, and 2012: an analysis of national surveys. Lancet 2013; 381: 1756-62.

4. World health organization. Contraceptive prevalence rate 2015. Available at: https://www.who.int/ healthinfo/indicators/ 2015/chi_2015_75_contraceptive_prevalence.pdf?ua=1.

5. Gaffield ML, Kiarie J. WHO medical eligibility criteria update. Contraception 2016; 94(3): 193-4.

6. Asghar S, Homayun A, Awan F. The Future of Post Placental Intrauterine Contraceptive Device (PPIUCD) in Pakistan. Pak J Med Sci 2016; 10(1): 320-22.

7. Gupta A, Verma A, Chauhan J. Evaluation of PPIUCD versus interval IUCD (380A) insertion in a teaching hospital of Western UP. Int J Reprod Contracept Obstet Gynecol 2013; 2(2): 204-48.
8. Batool M, Mazhar SB. Immediate postpartum and post abortion long acting reversible contraception in referral level facility: time to make up for lost opportunities. Pak J Surg Gynaecol Obstet 2017; 7(4): 196-99.

9. Mohamed SA, Kamel MA, Shaaban OM, Salem HT. Acceptability for the use of postpartum intrauterine contraceptive devices: Assiut experience. Med Princ Pract 2003; 12(3): 170-75.

10. Mishra S. Evaluation of safety, efficacy, and expulsion of postplacental and intra-cesarean insertion of intrauterine contraceptive devices (PPIUCD). J Obstet Gynaecol India 2014; 64(5): 337-43.

11. Khokhar S, Rizwan W, Tayyab M. Complications and safety of intra-caesarean insertion of IUCD. Pak J Med Health Sci 2018; 12(1): 595-97.

12. Suboohi S, Abbasi S, Pario S. Outcome of immediate PPIUCD at follow up visit in women at a tertiary care hospital in Karachi, Pakistan. J Bahria Uni Med Dental Coll 2019; 9(1): 43-47.

13. Nahar K, Fatima P, Dewan F, Yesmin A, Laila T, Begum N, et al. Acceptability and feasibility of postpartum intrauterine contraceptive device insertion in bangabandhu sheikh mujib medical university, Dhaka, Bangladesh. Bio Med J 2019; 47(3): 25-31.

14. Khalid T, Yousaf T, Irum S, Javed U. Post placental intrauterine contraceptive device insertion: a promising contraceptive approach. Pak Armed Forces Med J 2019; 69(5): 1115-19.

15. Gujju RL, Prasad U, Prasad U. Study on the acceptance, complications and continuation rate of postpartum family planning using the post placental intrauterine contraceptive device among women delivering at a tertiary care hospital. Int J Reprod Contracept Obstet Gynecol 2015; 4(2): 388-91.

16. Cordes S. Postpartum intrauterine device placement: A patientfriendly option. Contracept Reprodcut Med 2018; 3(1): 3-8.

17. Katheit G, Agarwal J. Evaluation of post-placental intrauterine device (PPIUCD) in terms of awareness, acceptance, and expulsion in a tertiary care centre. Int J Reprod Contracept Obstet Gynecol 2013; 2(4): 539-43.

18. Hooda R, Mann S, Nanda S, Gupta A, More H, Bhutani J. Immediate postpartum intrauterine contraceptive device insertions in caesarean and vaginal deliveries: a comparative study of follow-up outcomes. Intl J Reprod Med 2016; 2016: 1-5.

19. Roy LC, Shivakumar RN, Paprikar MM. To study the safety and efficacy of post-partum intra-uterine contraceptive device. Intl J Res Rev 2019; 6(10): 252-58.

20. Katheit G, Agarwal J. Evaluation of post-placental intrauterine device (PPIUCD) in terms of awareness, acceptance, and expulsion in a tertiary care centre. Int J Reprod Contracept Obstet Gynecol 2013; 2(4): 539-43. 